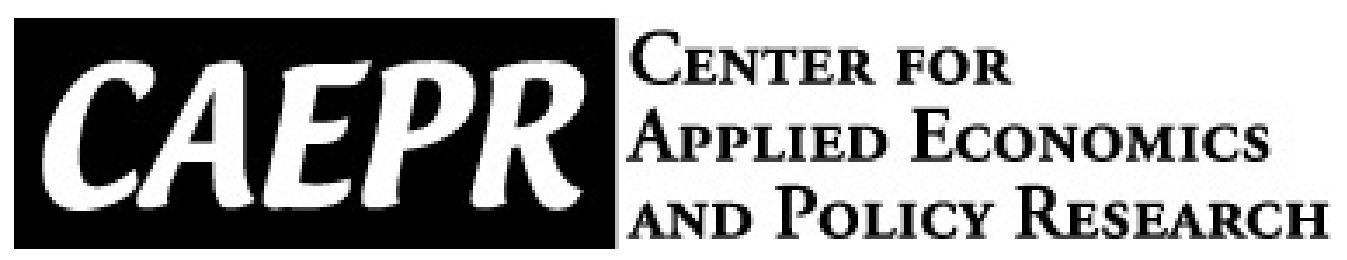

CAEPR Working Paper

\#003-2010

\title{
External Matching Funds and the Provision of Public Goods: An Experimental Study
}

\author{
Ronald J. Baker II \\ University of Pennsylvania
}

James M. Walker

Indiana University

\section{Arlington W. Williams \\ Indiana University}

February 2010

This paper can be downloaded without charge from the Social Science Research Network electronic library at: http://ssrn.com/abstract=1555871.

The Center for Applied Economics and Policy Research resides in the Department of Economics at Indiana University Bloomington. CAEPR can be found on the Internet at:

http://www.indiana.edu/ caepr. CAEPR can be reached via email at caepr@indiana.edu or via phone at 812-855-4050.

(C2008 by NAME. All rights reserved. Short sections of text, not to exceed two paragraphs, may be quoted without explicit permission provided that full credit, including $\odot$ notice, is given to the source. 


\title{
External Matching Funds and the Provision of Public Goods: An Experimental Study
}

\author{
Ronald J. Baker II † \\ Department of Economics \\ Millersville University of Pennsylvania \\ PO Box 1002 \\ Millersville, PA 17551 \\ Phone: 1-717-872-3560 \\ Fax: 1-717-871-2326 \\ (ronald.baker@millersville.edu) \\ James M. Walker \\ Department of Economics \\ Indiana University - Bloomington \\ 105 Wylie Hall \\ Bloomington, IN 47405 \\ (walkerj@indiana.edu) \\ Arlington W. Williams \\ Department of Economics \\ Indiana University - Bloomington \\ 105 Wylie Hall \\ Bloomington, IN 47408 \\ (williama@indiana.edu)
}

February 2010.

Please do not quote without permission.

\begin{abstract}
The voluntary provision of a pure public good is studied in the presence of an anonymous external donor. New data generated using experimental procedures employing both extra-credit and cash incentives, as well as asynchronous access to real-time decision rounds lasting several days, are compared to previous data generated using traditional cash-only, synchronous-access laboratory procedures. The effect on resource allocations to the public good of introducing external matching funds is examined in two different settings, lump-sum matching and one-to-one matching. The new data confirm the robustness of results previously reported by the authors to the change in laboratory procedures and incentives. The new data are then used to extend the parameter space in which the two matching mechanisms are studied, including: varying within-round information regarding the current level of public-good allocations, varying the marginal rate of return from the public good, and varying group size from four to twenty group members.
\end{abstract}

JEL Classification: C91, H41

$\uparrow$ Corresponding Author

*Research support from the Indiana University Center on Philanthropy is gratefully acknowledged. 


\section{Introduction}

The research reported here builds on Baker et al. (2009). In that study laboratory experiments are used to examine the voluntary provision of a pure public good in the presence of an anonymous external donor. The external funds are used in two different settings, lump-sum matching and one-to-one matching, to examine how allocations to the public good are affected. The results reveal that allocations to the public good under lump-sum matching are significantly higher, and have significantly lower within-group dispersion, relative to one-to-one matching and two baseline settings without external matching funds. In addition, a comparison of two baseline conditions reveals a positive framing effect on public goods allocations when it is explicitly revealed to participants that an outside source has made an unconditional allocation to the public good. The experiments reported in this study are designed to examine the robustness of the results reported in Baker et al. (2009) as well as broadening the parameter space in which the two matching mechanisms are studied. The experiments incorporate the methodology developed by Isaac et al.(1994, 2001), where there are three important procedural modifications relative to traditional laboratory experiments (where participants arrive at the lab, the relevant behavior data are collected, and participants depart after receiving a cash payment at the session's conclusion): 1) decisionmaking rounds last several, typically 3.5 , days rather than a few minutes, 2) participation is via any networked computer at any time during a multi-day decision round, and 3) course extra-credit rewards, based on both participation and performance, are utilized in addition to the possibility of a performancebased cash payment.

Laboratory experimental research on the provision of public goods has focused primarily on decision making in what is referred to as the voluntary contributions mechanism (VCM). In the most standard VCM decision setting, a group is comprised of a fixed number of individuals. Each individual is endowed with resources that can be allocated to either a private good that benefits only the individual (the private account) or to a pure public good that benefits all members of the group (the group account). The benefits are structured so that group earnings are maximized if all endowed resources are allocated to the group account. Each individual, however, has an incentive to free ride on the group-account allocations of other group members by allocating their resource endowment to the private account. 
One topic addressed in the experimental public goods literature is institutional arrangements that reduce collective action problems by creating incentives that facilitate cooperation. The research reported here examines voluntary contributions to a public good in the presence of an external source of resources that are used for matching the contributions of group members. Two matching settings are examined. In the first, referred to as lump-sum matching, a publicly announced fixed level of resources from the external source flow to the group account only if the internal contributions of group members reach or exceed a pre-announced threshold level. In the second, referred to as one-to-one matching, each resource unit contributed to the group account is matched by the external source up to a publicly announced maximum level. Undertaking a controlled laboratory comparison of these alternative matching-fund settings is motivated by the observation that both arrangements are commonplace in fund drives for the provision of public goods in field settings (e.g. public radio fund drives). ${ }^{1}$

These changes in experimental settings can be thought of in the following way. Assume a public good is to be partially funded through voluntary contributions. Further assume that the fund drive organizers have prior funding commitments that can be used for matching other potential donors' contributions. From the perspective of agencies receiving contributions, the strategic question is what type of institution makes best use of the matching funds. As discussed below, in the standard VCM environment matching funds create incentives where equilibrium strategies exist that imply non-zero provision of the public good.

The free-rider problem is particularly relevant for charitable giving, volunteerism, and other forms of philanthropy. While some of these activities can no doubt be rationalized as privately optimal, and in this respect no different from other economic activities, a significant amount of these activities entails personal sacrifices in order to improve social outcomes. This research is informative about the origin of such behaviors and their maintenance within social groups, since experiment participants experience similar incentives, albeit in a more abstract setting. By focusing on such a setting, the effect of economic incentives per se is investigated and comparisons are made that control for other factors that may affect behavior. In this context, the research reported here studies the role of alternative

\footnotetext{
${ }^{1}$ See List (2008), and other articles in a special issue of Experimental Economics that is devoted to field experiments focusing on charitable giving.
} 
philanthropic institutions for promoting charitable contributions and explores how such institutions affect individual incentives, behavior, and resulting group outcomes relative to a known socially optimal outcome that maximizes the group's monetary earnings. ${ }^{2}$

The paper is organized as follows. Section 2 provides details of the experimental procedures and design. Section 3 presents experimental results, and Section 4 contains a summary of conclusions.

\section{Decision Settings, Procedures, and Design Summary}

\subsection{The Decision Settings}

All experimental sessions utilized a variation of the VCM framework of Isaac et al. (1994), henceforth referred to as the standard VCM setting. Individuals made decisions in fixed groups of size N. At the start of each round, individual i was endowed with $Z_{i}$ tokens which were then allocated by $i$ between a private account, earning a constant return of $p_{i}$ per token, and a group account, earning a return based upon the total number of tokens allocated by the group. Tokens could not be carried across rounds. For a given round, let $\mathrm{m}_{\mathrm{i}}$ represent individual i's allocation of tokens to the group account and $\sum \mathrm{m}_{\mathrm{j}}$ represent the sum of tokens placed in the group account by all other individuals $(j \neq i)$. Each individual earned $\left[\mathrm{G}\left(\mathrm{m}_{\mathrm{i}}+\sum \mathrm{m}_{\mathrm{j}}\right)\right] / \mathrm{N}$ cents from the group account. Because each individual received a $1 / \mathrm{N}$ share of the total earnings from the group account, the group account was a pure public good. At the end of each round, decision makers were informed of their group's allocation to the group account, as well as their earnings for that round. Decision makers were not informed of the individual decisions of other group members.

Most of the decision-making groups were comprised of $\mathrm{N}=4$ individuals with per-round token endowments of $Z=25$. In addition, in the results section below, an initial exploration of group-size effects will be reported using twenty-person groups. For groups where $\mathrm{N}=4$, the return from each individual's private account was one cent per token, and a four-person group's return from a token placed in the group account was $\mathrm{G}^{\prime}(\cdot)=2.4$ cents in the MPCR $=0.6$ condition and $\mathrm{G}^{\prime}(\cdot)=1.2$ cents in the MPCR $=0.3$ condition. The marginal per-capita return from the group account (MPCR) is the ratio of private monetary benefits to private monetary costs for moving one token from the private account to the group

\footnotetext{
${ }^{2}$ See Baker et al. (2009) for a discussion of related studies.
} 
account. In addition, experimental sessions (with MPCR $=0.6$ ) varied the information decision makers received within rounds regarding allocations to the group account. In the no-information condition, decision makers received no within-round information regarding other group members' decisions. In the information condition, decision makers were provided current information on the group's aggregate allocation to the group account. Decision makers were informed, however, that at any time within a round group members were allowed to change their current decisions. That is, group-account allocations were not final until a round ended. How decision makers may respond to within-round information is a behavioral question. As discussed below, however, some of the decision settings allow for multiple equilibria over individual allocations to the group account. Clearly, such information may allow decision makers to better coordinate over such equilibria, in particular, symmetric equilibria. As in Isaac et al. (1994) and Baker et al. (2009), decision makers in all settings received end-of-round information on their group's aggregate allocation to the group account, as well as their own payoff for the round. All settings included ten decision rounds, and this was known prior to beginning of the first round.

As discussed in previous studies, under the assumption that it is common knowledge that decision makers maximize own-earnings and play a finitely repeated game with a commonly known end point, the subgame-perfect noncooperative Nash equilibrium in this standard VCM setting is for each decision maker to allocate zero tokens to the group account. As discussed below, however, the settings that incorporate matching funds have important consequences for equilibrium predictions. Finally, note that the payoff dominant Pareto optimum in the standard VCM setting, and for all settings investigated in this study, is for decision makers to allocate all tokens to the group account.

Lump-Sum Matching In addition to the instructions for the standard VCM setting, decision makers were informed that if total allocations to the group account met or exceeded 60 tokens, the group account would automatically have an additional 60 tokens added to it from an "external source" of tokens, with the earnings from these additional tokens being identical to those allocated by group members. ${ }^{3}$

\footnotetext{
${ }^{3}$ Participants were explicitly informed that the external source was a computerized robot player, and loaded words such as "donor" or "contributor" were not used to describe the external source. Similarly, tokens were "allocated" to the group account, rather than "donated" or "contributed". Instructions are available from the authors upon request.
} 
Regardless of whether the MPCR condition was 0.6 or 0.3 , the lump-sum matching creates a discontinuity in the payoffs associated with the group account at the point where the decision makers meet the minimum threshold of 60 tokens. This property of the payoff function implies strategic elements to the game that lead to alternative Nash equilibria. In particular, similar to experiments with provision points, there are now multiple Nash equilibria. While all individuals allocating zero tokens to the group account remains a Nash equilibrium, the group income-maximizing Nash equilibrium is to meet the lumpsum matching threshold exactly. Thus, the symmetric Nash equilibrium is 15 tokens from each group member, but any other (asymmetric) combination of group-account allocations that exactly meet the lump-sum match threshold is also a Nash equilibrium. ${ }^{4}$ From a noncooperative perspective, decision makers have an incentive to free ride on the allocations of others if they expect others to allocate sufficient funds to the group account to meet the lump-sum matching threshold. On the other hand, from a game-theoretic perspective, the symmetric Nash equilibrium of 15 tokens per group member may serve as a focal point for decision makers (see Marks and Croson, 1998).

It is important to note a key difference between this setting and the provision-point setting. In the lump-sum setting, if allocations to the group account do not meet the minimum requirement of 60 tokens, those tokens allocated by group members are still utilized as group-account allocations and generate earnings for the group. In the provision-point environments studied to date, if group-account allocations do not meet the provision point, those tokens are either refunded to the private account or lost, depending upon the particular setting under investigation.

One-to-One Matching Decision makers were informed that each token allocated to the group account, up to a group maximum of 60 , automatically led to an additional token being added to the group account from an external source. The group account earnings generated by each additional external token was identical to those internally allocated by the four group members.

\footnotetext{
${ }^{4}$ To see this, consider the most extreme case in which MPCR $=0.3$ and where other group members are assumed to allocate, in aggregate, 35 tokens to the group account. Now suppose individual "i" allocates all of his/her endowment, 25 tokens, to the group account to meet the 60-token match. Individual i gains an additional $\$ 0.18$ $(\$ 0.003 * 60)$ from the lump-sum match and loses $\$ 0.175((\$ 0.01-\$ 0.003) * 25)$ from his/her group-account allocation of 25 tokens.
} 
The experiments with one-to-one matching create an increase in the marginal gain from allocations to the group account up to the maximum level of matching. In the MPCR $=0.6$ condition, oneto-one matching implies an MPCR of 1.2 for group-account allocations up to 60 tokens. This property of the payoff function implies the existence of multiple Nash equilibria. In particular, an allocation to the group account that is matched yields a marginal return to the group member above the $\$ 0.01$ per-token opportunity cost. In this setting, all group members allocating zero tokens to the group account is no longer a Nash equilibrium. As with lump-sum matching, there are multiple Nash equilibria where group members' total allocations to the group account exactly meet the maximum level of matching, and the symmetric equilibrium may serve as a focal point. From a noncooperative perspective, decision makers have an incentive to free ride if they expect others' group-account allocations to be sufficient to extract the maximum level of matching funds. In the MPCR $=0.3$ condition, however, one-to-one matching implies an MPCR of 0.6 for group-account allocations up to 60 tokens. Thus, this parameterization does not affect the sub-game perfect noncooperative Nash equilibrium (zero tokens to the group account) based on the assumption that decision makers are maximizing own earnings.

Note that the earnings consequences of some aggregate allocations in the one-to-one setting differ substantially from those in the lump-sum setting. In particular, in both settings decision makers face the problem of coordinating who will provide the group-account allocations to be matched. The penalty, however, for not meeting the full-match threshold in the lump-sum setting is larger than in the one-to-one setting. In the lump-sum setting, the penalty is $\$ 0.36$ per individual when the MPCR $=0.6$ and $\$ 0.18$ per individual when the MPCR $=0.3$, regardless of how close the total group allocation is to the threshold. In the one-to-one setting, the penalty per individual is $\$ 0.006$ for each token the group falls short of the maximum level of matching in the MPCR $=0.6$ condition and $\$ 0.003$ in the MPCR $=0.3$ condition. Thus, falling a few tokens short of the threshold in the lump-sum setting has a relatively large negative effect on earnings, while an identical group-account allocation in the one-to-one setting has a much smaller effect. Focusing on this difference in the group-account earnings functions leads to the conjecture that lump-sum matching will generate greater group-account allocations than one-to-one matching. On the other hand, in the treatment condition where MPCR $=0.6$, if group members in the one-to-one setting realize that 
matching results in the marginal private benefit of a token allocated to the group account exceeding the marginal private cost $(\mathrm{MPCR}=1.2)$, an alternative conjecture is that the one-to-one setting will lead to a higher level of group-account allocations. Thus, standard theoretical considerations do not yield a clear prediction as to differences across the two settings in the level of allocations to the group account for the $\mathrm{MPCR}=0.6$ condition. On the other hand, for the MPCR $=0.3$ condition, this logic implies that lumpsum matching is expected to yield higher group-account allocations since the marginal private benefit of a token allocated to the group account remains below the marginal private cost in one-to-one matching.

\subsection{Procedures}

Participants were volunteers from undergraduate microeconomic theory classes (intermediatelevel honors and non-honors sections, and introductory-level honors sections) at Indiana UniversityBloomington from the Fall 2004 to Fall 2009 semesters. There were nine experimental sessions, where an experimental session consisted of a semester where decision-making groups were randomly constructed using students enrolled in microeconomics classes offering optional participation in the VCM exercise. Table 1 provides a summary of the experimental design utilizing four-person groups. There are 108 decision-making groups across the nine experimental sessions with ten rounds per group yielding a total of 4320 individual decisions. All students attending these classes received a handout (see Appendix) explaining the rules for participation. In summary, the handout informed students: 1) of the basic nature of the group decision-making exercise, 2) that participation is voluntary and will result in their earning extra-credit points and the possibility of performance-based cash payment, 3) of the specific formula used to convert the cash earnings reported to them by the computer into extra-credit points and the potential to earn a cash payment, 4) of the days associated with each of the ten decision rounds in an experimental session, 5) of the specific procedures for accessing the exercise on their personal computer or in a computing lab, and 6) that upon first accessing the exercise they will be shown an informed-consent statement approved by the Committee for the Protection of Human Subjects and must then choose whether or not to grant or deny the use of their decisions for research purposes. The following specific points describe the nonstandard "multiple-session" or "asynchronous-access" experimental procedures utilized in this research. 
1. The NovaNET VCM software handles many independent decision-making groups running simultaneously. Before beginning an experimental session, the experimenter initializes a set of parameters for each decision-making group. For example, one session might consist of several classes with a combined participation of 80 students who were then randomly assigned to four-person groups. In the research reported here, most groups were initialized with a group size of four, with a few twentyperson groups used to explore group-size effects. Each session also included groups facing different treatment conditions. After the session was completed, this design feature allowed for in-class discussion of the affects of alternative institutional arrangements in the voluntary funding of public goods.

2. Upon logging onto the computer for the first time, students are assigned to a decision-making group via a quasi-random rotation procedure unknown to the students. This reduces the probability that several acquaintances accessing round one at the same time will be assigned to the same group. As part of the initialization process, the experimenter designates each potential group as either "primary" or "secondary." All primary groups are filled before remaining students are assigned to secondary groups, the objective being to ensure a set of fully-populated primary groups since the participation rate in a voluntary exercise is uncertain. Inevitably, some students do not meet the deadline for entering their round-one decision and are thus excluded from participation in the exercise. ${ }^{5}$

3. After logging in for the first time, students work through a set of instructions at their own pace and then enter their allocation decision for round one. After entering a decision, the student exits the software but can reenter at any time to modify the decision.

4. Students are allowed to proceed to the next decision round only after the "current round" parameter is automatically advanced by the software (based on the system clock in conjunction with a length-of-round parameter specified during initialization). ${ }^{6}$ Upon logging on for subsequent rounds, students are shown the results of the previous round and then routed directly to the decision entry display

\footnotetext{
${ }^{5}$ The research database includes nine experimental sessions with 56, 60, 56, 64, 52, 24, 12, 48, and 60 participants, respectively. Statistical analysis of data from fully-populated "primary" versus "secondary" groups indicates no significant difference in mean group-account allocations, so the research database includes both. Any group that is not fully populated with students is filled out with robot players that always allocate 15 tokens to the group account, and the human players are informed of this upon logging in for round 2. Groups with robot players are excluded from the research database analyzed in this paper, as are groups where any participant declined consent to allow their decisions to be used for research purposes. Less than $2 \%$ of students choose to decline consent.

${ }^{6}$ Decision rounds lasted 3.5 days, except for a few rounds that spanned Thanksgiving or spring break and the first round, which typically lasted about one week from the time the launch handout was distributed (see Appendix).
} 
for the current round. At this point, students have the option to review the instructions and to view the results from all prior rounds.

5. As in many field experiments, there is no guarantee that all students assigned to a group will $\log$ on and enter an allocation decision in each round. For this reason, the software allows the student to specify a default allocation decision for subsequent rounds. The default allocation for missed rounds can be changed at any time, and the procedure for handling defaults is carefully explained to students as part of the instructions. The experimental results presented in the next section suggest that the count of default decisions in a round does not significantly affect group-account allocations.

The multiple-session asynchronous-access experimental procedures outlined above represent a logical link between traditional single-session synchronous-access laboratory experiments and field experiments. In such "flaboratory" environments, some experimental control is lost relative to a strictly controlled laboratory setting, however, the gain in feasible group sizes, the real time between allocation decisions, and the more natural communication and learning opportunities add an element of parallelism with non-experimental settings that could have important methodological and behavioral ramifications.

Extra-credit Performance Index As explained in the class handout (see Appendix), student i's experimental dollar earnings were converted into the following "performance index" prior to being converted into extra-credit points:

\section{i's Actual Earnings - i's Minimum Possible Earnings}

i's Maximum Possible Earnings - i's Minimum Possible Earnings

which can range from 0 to 1 for each individual. The performance index was used so that the maximum and minimum possible extra-credit earnings did not depend upon the group assignment. At the end of the final round, a performance index was computed for each student (based on earnings in all rounds), multiplied by a predetermined maximum number of performance-based extra-credit points, and then added to the students' grade average. Students also earned participation-based extra credit determined by the number of rounds in which they logged into the exercise and entered an allocation decision. All classes from which students were drawn utilized a 100-point scale and, with minor modifications, used a standard mapping of point totals into letter grades $(A=90$ 's, $B=80$ 's, etc. $)$. Furthermore, Indiana 
University allows + and - letter grades, so a unique letter grade typically comprised a 3 to 4 point interval. $^{7}$

As discussed in Isaac et al. (1994, 2001), we have spent a great deal of time considering questions of practicability and fairness in the use of extra-credit points as a motivator. It is important to realize that our extra-credit experiments always have a clear pedagogical objective and become an integral part of our in-class discussions of private versus external benefits, public-goods provision, free riding, and the Nash equilibrium concept. Our research procedures were thoroughly reviewed and approved by the Indiana University Committee for the Protection of Human Subjects. On the issue of fairness, thousands of students have participated in the VCM exercise using extra-credit rewards and there have been no grade appeals in which extra credit was an issue. In fact, anonymous feedback from students on course evaluations (and from other faculty who have adopted similar exercises for purely pedagogical purposes) has been quite positive. It is perhaps worth noting that post-exercise in-class discussion tends to focus on external benefits, the potential social gains from cooperation, and philanthropy as distinct from the traditional behavioral assumptions of noncooperative game theory.

Cash Payments In addition to extra credit, participants in each experimental session had the opportunity to earn cash. After the session was concluded, the experimenters randomly drew a random permutation of numbers associated with names from the set of participants. The first student whose name was drawn earned cash equal to four times their earnings in the exercise. This random selection process continued until the total paid out was greater than or equal to $\$ 100$, at which time the cash payments stopped. That is, for example, if the sixth cash payment raised total payments from, for example, $\$ 90.50$ to $\$ 110.25$, that student would receive their full $\$ 19.75$ earnings, making the total payout $\$ 110.25$. This very simple cash incentive system appeared to inject additional interest in the exercise and the presentation of payments to the lucky cash winners was an entertaining precursor to in-class discussions of the results. Whether or not this non-standard mixed reward structure significantly affects behavior in the VCM with external matching funds is an empirical issue that will be addressed in the next section as part of the presentation of experimental results.

\footnotetext{
${ }^{7}$ The weight given to extra-credit points varied across instructors from $3 \%$ to $1 \%$ of the overall semester grade, half based on performance and half based on participation.
} 


\section{Results}

Data generated using the multiple-session, asynchronous-access experimental procedures with extra-credit and cash rewards (henceforth denoted MSEXP) are analyzed in the following ways. First, to examine the potential behavioral effect of using MSEXP procedures, group-account allocations from MSEXP groups are compared to allocations generated using traditional single-session cash-only procedures (henceforth denoted SSEXP) reported in Baker et al. (2009). ${ }^{8}$ Second, the impact on groupaccount allocations of altering within-round information and MPCR using MSEXP procedures is explored. Third, an initial evaluation of the impact on group-account allocations of a five-fold increase in group size is conducted. Finally, differences in allocations at the individual level due to the influence of the above experimental treatments are considered.

\subsection{Comparison of Allocations using SSEXP vs. MSEXP Procedures}

Figure 1 displays the four round-by-round time series of mean allocations to the group account for the both the one-to-one and lump-sum matching settings using either MSEXP or SSEXP procedures (with group size $=4, \mathrm{MPCR}=0.6$, and no within-round information). In the one-to-one setting, the use of MSEXP procedures does not appear to have a significant impact on group-account allocations relative to those observed using traditional SSEXP procedures. In the lump-sum setting, however, some separation in mean group-account allocations between SSEXP and MSEXP occurs after round 4. The statistical significance of this separation is addressed below. Consistent with the results reported in Baker et al. (2009) employing SSEXP procedures, allocations using MSEXP procedures tend to be higher in the lump-sum setting relative to the one-to-one setting.

A random-effects panel-data model estimated by GLS is used to test the observations drawn from Figure 1. The model is estimated using 530 group-level observations (24 groups in SSEXP and 29 groups in MSEXP), where tokens allocated to the group account by four-person groups (the aggregate allocation excluding external matching tokens) is the dependent variable. The independent variables are: a lumpsum matching dummy variable (LUMP), a multiple-session procedures dummy variable (MSEXP), an

\footnotetext{
${ }^{8}$ Participants in Baker et al. (2009) made decisions in a three-phase experiment where the matching setting varied by phase. Only phase-one data from the SSEXP experiments reported in Baker et al. (2009) are used in the comparison to the MSEXP data. There are twelve phase-one groups in both the SSEXP lump-sum setting and the SSEXP one-to-one setting.
} 
interaction variable of lump-sum matching with the MSEXP treatment (LUMPxMSEXP) that allows for the matching settings to differently impact the MSEXP treatment, and nine decision-round dummy variables ( $\mathrm{RNDi}, \mathrm{i}=2,3, \ldots, 10)$. Thus, the constant term provides the predicted group-account allocation for round one using the one-to-one setting and SSEXP procedures. To account for lack of independence across the ten decision rounds generated by each of the 53 four-person groups, robust standard errors are utilized where the data are clustered by these within-group observations. ${ }^{9}$ Unobserved heterogeneity associated with each of the ten experimental sessions (two using MSEXP procedures and eight using SSEXP procedures) is modeled as a random-effect error component. Table 2a displays regression coefficient point estimates, clustered robust standard errors, and two-tailed significance tests of the coefficients; for presentational compactness the decision-round dummy variables are not displayed. Table $2 \mathrm{~b}$ displays Wald tests of the effect of varying experimental procedures for a given matching setting, as well as the effect of varying the matching setting for a given experimental procedure. ${ }^{10}$

The results reported in Tables $2 \mathrm{a}$ and $2 \mathrm{~b}$ confirm that changing from SSEXP to MSEXP experimental procedures does not significantly impact group-account allocations. Consistent with Baker et al. (2009), allocations in the lump-sum setting are significantly larger than allocations in the oneto-one setting using either SSEXP or MSEXP procedures $(p=0.068, p=0.000$, respectively). Based on the insignificance of both the MSEXP coefficient $(\mathrm{p}=0.847)$ and a Wald test of MSEXP+LUMPXMSEXP $=0(\mathrm{p}=0.523)$, the null hypothesis of equal group-account allocations between SSEXP and MSEXP treatments is not rejected. This important result is consistent with the findings of Isaac et al. (1994), and motivates the use of MSEXP procedures to explore further the behavioral impact of external matching funds in the VCM.

Additional documentation of the effects of moving from traditional SSEXP to MSEXP procedures are provided in Tables $2 \mathrm{c}$ and $2 \mathrm{~d}$, which show round-by-round comparisons of the median and

\footnotetext{
${ }^{9}$ For a detailed discussion of the heteroskedasticity-robust Huber/White sandwich estimator of variance in clustered samples see, for example, Cameron and Trivedi (2005, Chapter 24, Section 24.5). The specific implementation utilized here is documented in Rogers (1993). The random-effects estimator is necessary because the experimentaltreatment dummy variables are round invariant, removing the possibility of using the fixed-effects estimator.

${ }^{10} \mathrm{~A}$ Wald test is used to test linear restrictions on regression coefficients by testing whether or not the regression under the restriction fits the data significantly worse than the unrestricted regression. The Wald test statistic asymptotically follows a chi-square distribution with degrees of freedom equal to the number of restrictions placed on the coefficients. See Cameron and Trivedi (2005, Chapter 7, Section 7.2.3) for details.
} 
variance of group-level allocations to the group account using either lump-sum (Table 2c) or one-to-one (Table 2d) matching. For each round in each matching setting there are 12 SSEXP observations and either 14 (lump-sum) or 15 (one-to-one) MSEXP observations (consistent with the group counts shown in Table 1). The nonparametric Mann-Whitney rank-sum statistic is used to test central-tendency equality, and the Levene statistic is used to test variance equality. The variance tests are motivated by the reduced reliance on cash incentives using MSEXP procedures and the Smith and Walker (1993) finding that lower monetary incentives tend to increase the variance of decision outcomes. Tables $2 \mathrm{c}$ and $2 \mathrm{~d}$ list the resulting p-value of these tests. ${ }^{11}$ Of the 20 round-by-round comparisons, only three rounds yield MannWhitney p-values less than 0.10 . The general insignificance of the Mann-Whitney tests reinforces the panel-data regression Wald tests in Table 2b. For the Levene variance tests, only two of 20 rounds yield p-values less than 0.10 . The general inability to reject either central-tendency equality or variance equality provides empirical justification for further explorations of the effects of external matching funds using MSEXP procedures.

\subsection{Explorations of Experimental Treatments using MSEXP Procedures}

As discussed in Section 2, in addition to the treatment conditions examined in Baker et al. (2009), MSEXP experimental sessions were conducted with MPCR $=0.6$ and within-round information on aggregate tokens to the group account, as well as MPCR $=0.3$ and no within-round information. The MPCR change has implications for Nash equilibria in the one-to-one setting, and adding within-round information may facilitate the ability of participants to focus on symmetric equilibria.

Figure 2 displays mean allocations to the group account for each treatment condition in both the lump-sum and one-to-one settings for each decision round. As shown in Figure 2a, decreasing the MPCR or providing within-round information appears to decrease mean group-account allocations for all rounds in the lump-sum setting. However, Figure $2 b$ illustrates that these changes in experimental conditions do not have a clear impact on mean group-account allocations in the one-to-one setting.

To formally test the observations drawn from Figure 2, a random-effects panel-data regression model estimated by GLS with clustered robust standard errors is utilized, as in Section 3.1. The

\footnotetext{
${ }^{11}$ Both the Mann-Whitney tests and the Levene tests assume that observations are independent across four-person groups, both across and within experimental sessions.
} 
dependent variable is the total group allocation to the group account (excluding external tokens). The independent variables are: a count of the number of participants within a group that used the default allocation for that particular round (DEFAULTS), a lump-sum matching dummy variable (LUMP), a within-round information dummy variable (INFO), a low-MPCR dummy variable (MPCR3), interaction variables of the lump-sum setting with the INFO and MPCR dummies (LUMPxINFO, LUMPxMPCR3), and nine decision-round dummy variables (RNDi, $\mathrm{i}=2,3, \ldots, 10) .{ }^{12}$ Thus, in this analysis the regression constant provides the predicted group-account allocation for round 1 in the one-to-one setting with MPCR $=0.6$ and no within-round information. The results of this regression are displayed in Table $3 \mathrm{a}$. Table $3 \mathrm{~b}$ displays Wald tests of the effect of varying the matching mechanism, MPCR, or within-round information, holding the other two treatment conditions constant.

The analysis confirms the informal observations drawn from Figure 2, and indicates that the count of default decisions using MSEXP procedures does not significantly affect group-account allocations. As revealed in the preceding subsection, group-account allocations in the MPCR $=0.6$ and no within-round information treatment are significantly greater in the lump-sum setting compared to the one-to-one setting $(\mathrm{p}=0.000)$. The Wald tests shown in Table $3 \mathrm{~b}$ do not, however, yield significant differences between the lump-sum and one-to-one settings when MPCR $=0.3$ (and no within-round information, $\mathrm{p}=0.856$ ), or when there is within-round information (and MPCR $=0.6, \mathrm{p}=0.163$ ). Thus, these results from alternative parameterizations call to question the environmental robustness of the Baker et al. (2009) conclusion that lump-sum matching is more effective than one-to-one matching in eliciting group-account allocations.

\footnotetext{
${ }^{12}$ Two additional panel-data random-effects models were estimated. The results reported in Table 3 are generally robust to these alternative model specifications. The first model is an individual-specific random-effects model utilizing cluster-robust standard errors where allocation decisions are clustered by the forty within-group observations (4 participants $\mathrm{x} 10$ rounds). The Wald tests based on this model are consistent with those shown in Table $3 \mathrm{~b}$ using group-level data. The second model is a two-limit censored-normal (Tobit) regression model with group-level cluster-robust standard errors. This model makes strong distributional assumptions to account for observations at the fixed upper and lower boundaries of group-account allocations. Only two percent of the observations on the dependent variable (23 of 1080) occur at the fixed upper boundary of $100 \%$ of tokens allocated to the group account, and only 3 observations occur at the lower boundary of zero. The Wald tests based on the Tobit model are consistent with Table $3 \mathrm{~b}$, except that the test of MPCR $3=0$ can be rejected with $p=0.073$. Thus, the (negative) impact of the lower MPCR on group-account allocations under one-to-one matching is marginally significant in this specification.
} 
The other Wald tests reveal that group-account allocations in one-to-one matching are not affected by either the lower MPCR $(\mathrm{p}=0.513)$ or providing additional within-round information $(\mathrm{p}=$ 0.973); however, the marginal effect of these environmental changes in lump-sum-matching is to significantly reduce group-account allocations $(\mathrm{p}=0.027$ and $\mathrm{p}=0.040$, respectively). For one-to-one matching, an unexpected result is that moving from $\mathrm{MPCR}=0.6$ to $\mathrm{MPCR}=0.3$ does not significantly affect group-account allocations. This is in spite of the fact that: 1) the lower MPCR eliminates interior Nash equilibria under standard noncooperative assumptions, and 2) there is considerable prior research documenting the existence of an MPCR effect for four-person VCM groups. This suggests the possibility of an external-match framing effect under one-to-one matching that negates or reduces the previously observed MPCR effect reported in Isaac et al. (1994).

To address this framing-effect conjecture, in addition to the experiments reported in Table 1 and analyzed in Table 3, 25 four-person groups with MPCR $=0.6$ and no external matching were conducted for comparison to the 25 groups with one-to-one matching and MPCR $=0.3 .^{13}$ Note that, for the first 60 tokens allocated to the group account, the effective MPCR is identical across these conditions. The research conjecture motivating this comparison was that an external-match framing effect would result in larger group-account allocations relative to the no-matching control groups. The data do not support the research conjecture -- a panel-data regression using cluster-robust standard errors and a session-specific random effect indicates that the coefficient on a one-to-one matching dummy variable is positively signed as predicted, but not significantly different from zero $(\mathrm{p}=0.632)$. If a framing effect exists under one-toone matching it is sufficiently subtle that it will be revealed as statistically significant only with a much larger sample of independent observations.

For lump-sum matching, both the lower MPCR and within-round information on tokens to the group account appear to have a disruptive effect on a group's ability to extract the external matching funds. While the negative MPCR effect can be rationalized based on the $50 \%$ reduction in the payoff spike from reaching the lump-sum matching threshold, the negative effect of providing within-round group-account information is more subtle. It appears that, when blind to others' aggregate group-account

\footnotetext{
${ }^{13}$ These 25 four-person groups without external matching are from three separate semesters, or "sessions", conducted at Indiana University-Bloomington and Millersville University of Pennsylvania.
} 
allocation in the current round, group members are more likely to allocate "insurance tokens" to increase the likelihood that the lump-sum threshold will be met. When group members have within-round information on others' current aggregate allocation, this tends to eliminate the insurance-allocation motive and promotes gaming focused on exactly meeting the lump-sum threshold. This results in, on average, smaller group-account allocations and a reduced probability of reaching the matching-tokens threshold. Having within-round information reduces the average count of rounds where the matching threshold is met from 8.5 to 6.1 out of 10 . This effect is significant using either a two-sample MannWhitney test of the count of rounds generating the lump-sum match in each group $(p=0.048$, sample size $=14,15$ ) or a logit regression with INFO as an explanatory variable for a binary dependent variable determined by whether or not a group meets (or exceeds) the match threshold in a given round ( 0 when no, 1 when yes, $p=0.058$ using the cluster-robust standard error, sample size $=290=29$ clusters of 10 observations).

\subsection{An Initial Exploration of Group-Size Effects}

To begin an exploration of the effects of changing group size, additional data were collected using MSEXP procedures, twenty-person groups, $\mathrm{MPCR}=0.6$, token endowment $=25$, and no withinround information on tokens to the group account. In order to parallel the four-person treatments, the group return from a token allocated to the group account, previously denoted as $G^{\prime}()^{\prime}$, is five times greater for the twenty-person groups. Also, the lump-sum match trigger and the full match for the one-to-one treatments were increased from 60 to 300 tokens. The analysis presented below is based on 26 twentyperson groups (13 groups in each match setting) involving 520 participants from three experimental sessions, where a session corresponds to a large Introduction to Microeconomics class at Indiana University-Bloomington. Since participants in the four-person groups were recruited from smaller, upper-level and honors introductory-level classes, the larger groups are considered separately to avoid potential confounding effects due to subject heterogeneity.

Figure 3 displays the mean group-account allocations for the large-group sessions by decision round. Consistent with the small-group sessions, mean allocations to the group account in the lump-sum setting are larger than mean group-account allocations in the one-to-one setting for all decision rounds. 
Further, mean allocations to the group account are below the full-match 300-token level in the one-to-one setting during the final three decision rounds. This contrasts with the lump-sum setting, where mean allocations to the group account remain above the 300-token threshold for the final nine rounds.

Table 4 presents GLS estimation of a panel-data regression model (with session-specific random effects and cluster-robust standard errors) to evaluate the statistical significance of changing match settings. The dependent variable is group-level tokens allocated to the group account (not including external tokens). The independent variables are: a count of the number of default allocations for a particular group and decision round (DEFAULTS), a lump-sum setting dummy variable (LUMP), and nine decision-round dummy variables (RNDi, $\mathrm{i}=2,3, \ldots, 10)$. The results reveal that the LUMP coefficient is positive and significant at the $5 \%$ level. Thus, consistent with the small-group results, allocations to the group account in the lump-sum setting are significantly higher than in the one-to-one setting when the MPCR $=0.6$ and there is no within-round information on tokens to the group account.

\subsection{Examining Allocations at the Individual Level for Four-Person Groups}

This subsection analyzes group-account allocations at the individual level organized around the frequency of occurrence of three benchmark allocations: the maximum (all 25 tokens), the symmetric Nash equilibrium (15 tokens), and complete free riding ( 0 tokens). ${ }^{14}$ Figure 4 displays the relative frequencies of these allocations across all decision rounds for the four-person groups using MSEXP procedures. In the lump-sum setting (Figure 4a), the most striking result is the relatively large observed frequency of the maximum allocation to the group account with $\mathrm{MPCR}=0.6$ and no within-round information. This is consistent with the previously-stated conjecture that participants in this high-MPCR, low-information environment are motivated to provide insurance tokens for meeting the 60-tokens matching threshold. Also noteworthy is how infrequently complete free riding occurs in this treatment. In the one-to-one setting (Figure 4b), the impact of providing within-round information is less striking than in the lump-sum setting, and an unanticipated result is the negligible impact of moving to the lower MPCR, where allocating fifteen tokens to the group account is no longer a symmetric Nash equilibrium.

\footnotetext{
${ }^{14}$ As mentioned in Section 2, the symmetric Nash equilibrium applies to all treatments except the MPCR $=0.3$ treatment in the one-to-one match setting. In this treatment the only Nash equilibrium is complete free riding by all group members.
} 
Apparently the fifteen-token benchmark still served as a coordinating mechanism for participants attempting to reach the full-match focal point.

To examine formally the statistical significance of the visual impressions rooted in Figure 4, negative-binomial count-data regressions are performed where the dependent variable is the number of rounds (an integer between 0 and 10) that an individual submitted one of the three specified benchmark allocations. The independent variables are the LUMP, INFO, and MPCR3 dummy variables and associated interaction terms described at the beginning of Section 3.2. ${ }^{15}$ Because each individual is part of a four-person group, an individual's token allocations are likely to be influenced by the previous allocations of other group members. To account for this within-group dependence, robust standard errors are reported where observations are clustered by decision groups. As in the previously reported regression results, the constant term provides the predicted outcome for the one-to-one setting with MPCR $=0.6$ and no within-round information on total tokens allocated to the group account.

Tables 5, 6, and 7 display the results of the negative-binomial regressions. A convenient way to interpret the regression coefficients in the negative-binomial model is to examine incidence-rate ratios (IRR), where IRR $=e^{\beta_{i}}$. IRRs reveal the percentage change in the expected count of a benchmark allocation due to a change in the treatment condition, holding all other independent variables constant. For example, in Table 5, the lump-sum setting increases the expected frequency for the maximum allocation by a multiple of 1.56 compared to the one-to-one setting, a $56 \%$ increase [i.e. $100 *(I R R-1)$ ].

Table 5 presents the results of the negative-binomial regression using the maximum groupaccount allocation as the dependent variable. The results confirm that when the MPCR $=0.6$ and there is no within-round information the expected frequency of maximum group-account allocations is significantly larger in the lump-sum setting than in the one-to-one setting. Wald tests are used to compare the lump-sum and one-to-one treatments under the other combinations of identical MPCR and information conditions. (The specific comparisons and associated null hypotheses are the same as those shown in Table 3b.) These tests yield no other significant differences in expected frequencies of

\footnotetext{
${ }^{15}$ A Poisson regression model was estimated first, but the results indicated that the assumption of equidispersion (equality of the mean and variance inherent in a Poisson process) must be rejected. Following Long (1997, Chapter 8 ) and Cameron \& Trivedi (2005, Chapter 20) the negative binomial model was utilized to capture overdispersion in the dependent variable.
} 
maximum allocations at the $10 \%$ significance level. In the lump-sum setting, Wald tests confirm that including within-round information $(\mathrm{p}=0.001)$ or lowering the MPCR $(\mathrm{p}=0.000)$ significantly decrease the expected frequency of maximum allocations relative to the high-MPCR, low-information treatment. In the one-to-one setting, only lowering the MPCR to 0.3 significantly decreases the expected frequency of maximum allocations $(\mathrm{p}=0.010)$.

Table 6 displays the results of the negative-binomial regression using the count of symmetric Nash equilibrium allocations as the dependent variable. The overall regression is not statistically significant. As suggested by Figure 4, no differences in expected frequencies occur across any pair-wise combinations of experimental treatments.

Table 7 displays the results of the negative-binomial regression using the count of complete freeriding allocations as the dependent variable. Comparing across the two matching settings with identical MPCR and information conditions, complete free riding when MPCR $=0.6: 1$ ) occurs significantly less often in the lump-sum setting when no within-round information is provided $(\mathrm{p}=0.003)$, and 2 ) occurs significantly more often in the lump-sum setting when within-round information is provided $(\mathrm{p}=0.004)$. There is no significant difference between the lump-sum and one-to-one settings in the expected frequency of complete free riding in the MPCR $=0.3$ treatment. Focusing on the lump-sum setting, Wald tests show that either the lower MPCR $(p=0.000)$ or including within-round information $(p=0.000)$ significantly increase the occurrence of complete free-riding allocations. In the one-to-one setting, however, the INFO and MPCR3 coefficients are not statistically significant at the $10 \%$ level. Once again, this is in spite of the fact that the only Nash equilibrium in the one-to-one setting when MPCR $=0.3$ is complete free riding.

\subsection{Examining Allocations at the Individual Level for Twenty-Person Groups}

This subsection focuses on examining the individual allocations to the group account for the larger group-size sessions. Similar to Section 3.4., the analysis focuses on the frequency of occurrence of three benchmark allocations: the maximum (all 25 tokens), the symmetric Nash equilibrium (15 tokens), and complete free riding ( 0 tokens). Figure 5 displays the relative frequency of occurrence for the benchmark allocations across all rounds for each match setting. The most frequently observed benchmark 
allocation for each setting is the maximum, while complete free riding occurs least often in each setting. The difference in the relative frequency of each benchmark allocation across matching settings is small. Complete free riding occurs $1.6 \%$ less often in the lump-sum setting, while both the symmetric Nash equilibrium and the maximum allocation occur more often in the lump-sum setting $(1.8 \%$ and $3 \%$, respectively). Count-data regressions are used to evaluate the statistical significance of the differences illustrated in Figure 5. The regression for each of the three benchmark allocations is not significant at the $10 \%$ level. Unlike the four-person groups, no significant differences in benchmark allocations occur between matching settings in twenty-person groups.

\section{Summary}

The research reported in this study extends and tests the robustness of the research reported in Baker et al. (2009). Both studies examine behavior in public-goods settings using two institutions found commonly in the field: lump-sum matching and one-to-one matching. The present research extends the previous study by examining treatment conditions with a lower marginal per-capita return from the group account, providing participants with information on total allocations to the group account within decision rounds, and examining behavior in larger groups. Participants in these experiments were student volunteers from microeconomics courses at Indiana University-Bloomington and Millersville University of Pennsylvania. They made decisions across rounds that lasted multiple days and were given participation and performance incentives in the form of course extra credit, with the possibility of earning performance-based cash awards. Thus, the experimental environment lies somewhere between traditional tightly-controlled laboratory experiments and field experiments - perhaps "flaboratory experiment" is an apt description. While resource endowments (tokens) are controlled and values are induced on the private and public good using a combination of extra-credit and cash rewards, communication opportunities and discussion of the decision-making problem are uncontrolled, arising endogenously both in class and out of class over decision rounds that typically last 3.5 days.

Decisions of participants using these nontraditional multiple-session procedures were first compared to decisions using traditional single-session procedures employing only cash rewards. Similar to Isaac et al. (1994, 2001), there is no significant difference in allocation decisions across the two types 
of procedures. Further, the main result reported by Baker et al. (2009) was also observed using the multiple-session procedures. Lump-sum matching elicits significantly larger allocations to the group account (the pure public good) than one-to-one matching when the MPCR (marginal per-capita return from a token allocated to the group account) is 0.6 and there is no within-round information provided on the current number of tokens allocated to the group account in four-person groups. This proceduralrobustness finding motivates the use of multiple-session procedures to extend the results of Baker et al. (2009) by exploring the effect of new treatment conditions on one-to-one versus lump-sum matching.

The new data, with groups of size four, reveal that internal allocations to the group account were sensitive to treatment changes in the lump-sum setting only. Within-round information on tokens allocated to the group account and a decrease in the MPCR from 0.6 to 0.3 both significantly reduced allocations to the group account in the lump-sum setting. These changes, however, did not significantly alter group-account allocations in the one-to-one setting. The net effect is that moving to MPCR $=0.3$ or providing within-round information eliminates the significant difference between lump-sum and one-toone matching.

In the lump-sum setting it was interesting to discover that providing within-round information has a disruptive effect on a group's ability to extract the external matching funds. In the one-to-one setting it was quite surprising to discover that moving from $\mathrm{MPCR}=0.6$ to $\mathrm{MPCR}=0.3$ did not significantly affect group-account allocations since use of the lower MPCR eliminates interior Nash equilibria that exist using the higher MPCR (under standard noncooperative behavioral assumptions). It is conjectured that framing allocation decisions in the context of one-to-one matching may overcome the MPCR effect documented in previous research using four-person groups. The existence of this framing-effect conjecture is tested using groups without opportunities for external matching and MPCR $=0.6$, which are equivalent to MPCR $=0.3$ with one-to-one matching (for internal group-account allocations that have not extracted the full match). While the framing effect is positively signed as expected, it is not statistically significant.

An initial exploration of a five-fold increase in group size, from four to twenty participants with MPCR $=0.6$ and no within-round information on current tokens allocated to the group account, reveals 
that the basic result from four-person groups (using either single-session or multiple-session procedures) is preserved - group-account allocations in the lump-sum match setting are significantly greater than in the one-to-one match setting.

Overall, given the decision-making environments studied so far, the experimental data suggest that lump-sum matching is at least as effective as one-to-one matching in eliciting voluntary contributions for the provision of a pure public good. The relative effectiveness of the lump-sum setting is improved if information on current aggregate contributions toward meeting the matching threshold is withheld, and in situations where the marginal per-capita valuation of the public good is relatively large. 


\section{References}

Baker, R., Walker, J., Williams, A., 2009. Matching Contributions and the Voluntary Provision of a Pure Public Good: Experimental Evidence. Journal of Economic Behavior and Organization 70, 122-134.

Cameron, A.C., Trivedi, P.K., 2005. Microeconometrics: Methods and Applications. Cambridge University Press, New York.

List, J., 2008. Introduction to Field Experiments in Economics with Applications to the Economics of Charity. Experimental Economics 11, 203-212.

Isaac, M., Walker, J., Williams, A., 1994. Group Size and the Voluntary Provision of Public Goods: Experimental Evidence Utilizing Large Groups. Journal of Public Economics 54, 1-36.

Isaac, R.M., Walker, J., Williams, A., 2001. Experimental Economics: Methods in the Large Undergraduate Classroom: Practical Considerations. In: Isaac, R.M., (Ed.), Research in Experimental Economics, vol. 8. JAI/Elsevier Science Press, Amsterdam, 1-23.

Long, J.S., 1997. Regression Models for Categorical and Limited Dependent Variables. SAGE Publications, California.

Marks, M., Croson, R., 1998. Alternative Rebate Rules in the Provision of a Threshold Public Good: An Experimental Investigation. Journal of Public Economics 67, 195-220.

Rogers, W.H., 1993. Regression standard errors in clustered samples. Stata Technical Bulletin Reprints 3, $88-94$.

Smith, V.L., Walker, J., 1993. Monetary Rewards and Decision Cost in Experimental Economics. Economic Inquiry 31, 245-261. 
Table 1. Design Summary: Number of Four-Person Groups by Treatment Condition

\begin{tabular}{lcccc}
\hline & \multicolumn{2}{c}{ Lump-Sum Matching } & \multicolumn{2}{c}{ One-to-One Matching } \\
& MPCR=0.6 & MPCR=0.3 & MPCR=0.6 & MPCR=0.3 \\
\hline $\begin{array}{l}\text { No Within-Round } \\
\text { Information }\end{array}$ & 14 & 24 & 15 & 25 \\
\hline $\begin{array}{l}\text { Within-Round } \\
\text { Information }\end{array}$ & 15 & 0 & 15 & 0 \\
\hline
\end{tabular}


Table 2a. Linear Model: Comparing Group-Level Allocations to the Group Account between SSEXP and MSEXP Procedures

\begin{tabular}{ccccc}
\hline $\begin{array}{c}\text { Independent } \\
\text { Variable }\end{array}$ & $\begin{array}{c}\text { Coefficient } \\
\text { Estimate }\end{array}$ & $\begin{array}{c}\text { Robust Clustered } \\
\text { Standard Error }\end{array}$ & \multicolumn{2}{c}{ Ho: Coefficient $=0$} \\
p-value
\end{tabular}

Total Number of Observations $=530 ; 53$ clusters of 10 observations

Model: $\chi 2(12)=73.03, \mathrm{p}=0.000$

Fraction of variance due to session-specific random effect: 0.0620

Nine decision-round dummies are included in model but not shown in table

Table 2b. Hypothesis Tests: Comparing Group-Level Allocations to the Group Account between SSEXP and MSEXP Procedures

\begin{tabular}{ccc}
\hline Conditional Means Compared & Ho for Wald Test & p-value \\
\hline MSEXP vs. SSEXP $\mid$ 1-to-1 & MSEXP $=0$ & 0.847 \\
MSEXP vs. SSEXP | LUMP-SUM & MS + (LUMPXMSEXP) $=0$ & 0.523 \\
1-to-1 vs. LUMP-SUM | SSEXP & LUMP $=0$ & 0.068 \\
1-to-1 vs. LUMP-SUM | MSEXP & LUMP + (LUMPxMSEXP) $=0$ & 0.000 \\
\hline
\end{tabular}

Table 2c. Nonparametric Tests for Lump-Sum Matching: Comparing Group-Level Allocations to the Group Account between SSEXP and MSEXP Procedures

\begin{tabular}{ccccccccccc}
\hline Decision Round & 1 & 2 & 3 & 4 & 5 & 6 & 7 & 8 & 9 & 10 \\
\hline SSEXP Median & 70.0 & 80.0 & 77.5 & 78.5 & 69.5 & 75.5 & 71 & 66.5 & 66 & 71.5 \\
MSEXP Median & 62.5 & 80.5 & 73.5 & 82 & 85 & 85 & 87.5 & 91.5 & 87.5 & 80.5 \\
SSEXP std. dev. & 12.7 & 10.3 & 13.1 & 13.2 & 15.2 & 13.0 & 11.6 & 14.4 & 15.7 & 9.6 \\
MSEXP std. dev. & 15.9 & 14.6 & 13.1 & 14.3 & 15.6 & 16.2 & 19.6 & 18.7 & 19.4 & 18.5 \\
Mann-Whitney test & 0.42 & 0.90 & 0.94 & 0.78 & 0.16 & 0.22 & 0.06 & 0.03 & 0.04 & 0.31 \\
Levene variance test & 0.55 & 0.12 & 0.78 & 0.89 & 0.91 & 0.25 & 0.15 & 0.25 & 0.21 & 0.02 \\
\hline
\end{tabular}

Table 2d. Nonparametric Tests for One-to-One Matching: Comparing Group-Level Allocations to the Group Account between SSEXP and MSEXP Procedures

\begin{tabular}{ccccccccccc}
\hline Decision Round & 1 & 2 & 3 & 4 & 5 & 6 & 7 & 8 & 9 & 10 \\
\hline SSEXP Median & 58 & 68.5 & 69.5 & 69 & 63.5 & 67 & 63.5 & 68.5 & 64 & 64 \\
MSEXP Median & 60 & 60 & 56 & 70 & 70 & 65 & 65 & 64 & 65 & 63 \\
SSEXP std. dev. & 11.2 & 14.0 & 12.4 & 14.5 & 14.5 & 15.3 & 14.6 & 15.2 & 17.1 & 19.4 \\
MSEXP std. dev. & 23.0 & 17.4 & 17.7 & 15.9 & 16.2 & 14.8 & 12.0 & 17.4 & 19.9 & 14.5 \\
Mann-Whitney test & 0.86 & 0.25 & 0.17 & 0.96 & 0.49 & 0.96 & 0.98 & 0.81 & 0.73 & 0.98 \\
Levene variance test & 0.00 & 0.42 & 0.10 & 0.69 & 0.34 & 0.76 & 0.55 & 0.91 & 0.66 & 0.55 \\
\hline
\end{tabular}


Table 3a. Linear Model: Comparing Treatment Effects with MSEXP Procedures

\begin{tabular}{ccccc}
\hline $\begin{array}{c}\text { Independent } \\
\text { Variable }\end{array}$ & $\begin{array}{c}\text { Coefficient } \\
\text { Estimate }\end{array}$ & $\begin{array}{c}\text { Robust Clustered } \\
\text { Standard Error }\end{array}$ & \multicolumn{2}{c}{ Ho: Coefficient $=0$} \\
CONSTANT & 57.7903 & 7.2507 & 7.97 & 0.000 \\
DEFAULTS & -1.3264 & 0.9717 & -1.37 & 0.172 \\
LUMP & 16.2125 & 4.4922 & 3.61 & 0.000 \\
INFO & -0.3435 & 10.0461 & -0.03 & 0.973 \\
MPCR3 & -5.8338 & 8.9161 & -0.65 & 0.513 \\
LUMPXINFO & -22.2894 & 6.2810 & -3.55 & 0.000 \\
LUMPXMPCR3 & -15.5005 & 5.9599 & -2.60 & 0.009 \\
\hline
\end{tabular}

Total Number of Observations $=1080 ; 108$ clusters of 10 observations

Model: $\chi 2(15)=91.33, p=0.000$

Fraction of variance due to session-specific random effect: 0.0592

Nine decision-round dummies are included in model but not shown in table

Table 3b. Hypothesis Tests: Comparing Treatment Effects with MSEXP Procedures

\begin{tabular}{ccc}
\hline Conditional Means Compared & Ho for Wald Test & p-value \\
\hline 1-to-1 vs. LUMP-SUM | NO INFO \& MPCR=.6 & LUMP $=0$ & 0.000 \\
1-to-1 vs. LUMP-SUM | NO INFO \& MPCR=.3 & LUMP+(LUMPxMPCR3) $=0$ & 0.856 \\
1-to-1 vs. LUMP-SUM | INFO \& MPCR=.6 & LUMP+(LUMPxINFO) $=0$ & 0.163 \\
NO INFO vs. INFO | 1-to-1 \& MPCR=.6 & INFO =0 & 0.973 \\
NO INFO vs. INFO | LUMP-SUM \& MPCR=.6 & INFO+(LUMPxINFO) $=0$ & 0.040 \\
MPCR=.6 vs. MPCR=.3 | 1-to-1 \& NO INFO & MPCR3 =0 & 0.513 \\
MPCR=.6 vs. MPCR=.3 | LUMP-SUM \& NO INFO & MPCR3+(LUMPxMPCR3) =0 & 0.027 \\
\hline
\end{tabular}

Table 4. Linear Model: Group Size 20

\begin{tabular}{ccccc}
\hline $\begin{array}{c}\text { Independent } \\
\text { Variable }\end{array}$ & $\begin{array}{c}\text { Coefficient } \\
\text { Estimate }\end{array}$ & $\begin{array}{c}\text { Robust Clustered } \\
\text { Standard Error }\end{array}$ & \multicolumn{2}{c}{ Ho: Coefficient $=0$} \\
p-value \\
\hline CONSTANT & 259.0495 & 11.4258 & 22.67 & 0.000 \\
DEFAULTS & -1.0688 & 1.0828 & -0.99 & 0.324 \\
LUMP & 17.4716 & 8.8636 & 1.97 & 0.049 \\
\hline
\end{tabular}

Total Number of Observations $=260 ; 26$ clusters of 10 observations

Model: $\chi 2(11)=215.54, p=0.000$

Fraction of variance due to session-specific random effect: 0.056

Nine decision-round dummies are included in model but not shown in table 
Table 5. Count-Data Model: Maximum Allocation

\begin{tabular}{cccccc}
\hline Independent & Coefficient & Robust Clustered & \multicolumn{2}{c}{ Ho: Coefficient $=0$} \\
Variable & IRR & Estimate & Standard Error & Z & p-value \\
\hline CONSTANT & & 1.0116 & 0.1469 & 6.89 & 0.000 \\
LUMP & 1.5584 & 0.4437 & 0.3194 & 2.16 & 0.030 \\
INFO & 0.8667 & -0.1431 & 0.2349 & -0.53 & 0.598 \\
MPCR3 & 0.5418 & -0.6128 & 0.1292 & -2.57 & 0.010 \\
LUMPxINFO & 0.4218 & -0.8632 & 0.1724 & -2.11 & 0.035 \\
LUMPXMPCR3 & 0.6998 & -0.3570 & 0.2336 & -1.07 & 0.285 \\
\hline
\end{tabular}

Total Number of Observations $=432 ; 108$ clusters of 4 observations

Model: $\chi 2(5)=30.62, \mathrm{p}=0.000$

Table 6. Count-Data Model: Symmetric Nash-Equilibrium Allocation

\begin{tabular}{cccccc}
\hline $\begin{array}{c}\text { Independent } \\
\text { Variable }\end{array}$ & IRR & Coefficient & Robust Clustered & \multicolumn{2}{c}{ Ho: Coefficient $=0$} \\
Estimate & Standard Error & Z & p-value \\
\hline CONSTANT & & 0.5404 & 0.1554 & 3.48 & 0.001 \\
LUMP & 1.1442 & 0.1347 & 0.3787 & 0.41 & 0.684 \\
INFO & 1.0000 & $1.55 \mathrm{E}-17$ & 0.2324 & 0.00 & 1.000 \\
MPCR3 & 0.9845 & -0.0157 & 0.2090 & -0.07 & 0.941 \\
LUMPXINFO & 1.1455 & 0.1358 & 0.4771 & 0.33 & 0.744 \\
LUMPXMPCR3 & 1.0504 & 0.0492 & 0.4046 & 0.13 & 0.898 \\
\hline
\end{tabular}

Total Number of Observations $=432 ; 108$ clusters of 4 observations

Model: $\chi 2(5)=2.45, \mathrm{p}=0.784$

Table 7. Count-Data Model: Complete Free-Riding Allocation

\begin{tabular}{cccccc}
\hline $\begin{array}{c}\text { Independent } \\
\text { Variable }\end{array}$ & IRR & Coefficient & Robust Clustered & \multicolumn{2}{c}{ Ho: Coefficient $=0$} \\
Estimate & Standard Error & $\mathrm{Z}$ & $\mathrm{p}$-value \\
\hline CONSTANT & & -0.5108 & 0.3656 & -1.40 & 0.162 \\
LUMP & 0.1786 & -1.7228 & 0.1044 & -2.95 & 0.003 \\
INFO & 0.5278 & -0.6391 & 0.2347 & -1.44 & 0.151 \\
MPCR3 & 1.4500 & 0.3716 & 0.6644 & 0.81 & 0.417 \\
LUMPXINFO & 17.0947 & 2.8388 & 12.0000 & 4.05 & 0.000 \\
LUMPxMPCR3 & 7.1073 & 1.9611 & 4.9746 & 2.80 & 0.005 \\
\hline \multicolumn{5}{c}{ Total Number of Observations $=432 ; 108$ clusters of 4 observations } \\
& Model: $\chi 2(5)=30.25, \mathrm{p}=0.000$ \\
\hline
\end{tabular}


Figure 1. Mean Internal Allocations to the Group Account: MSEXP vs. SSEXP Procedures

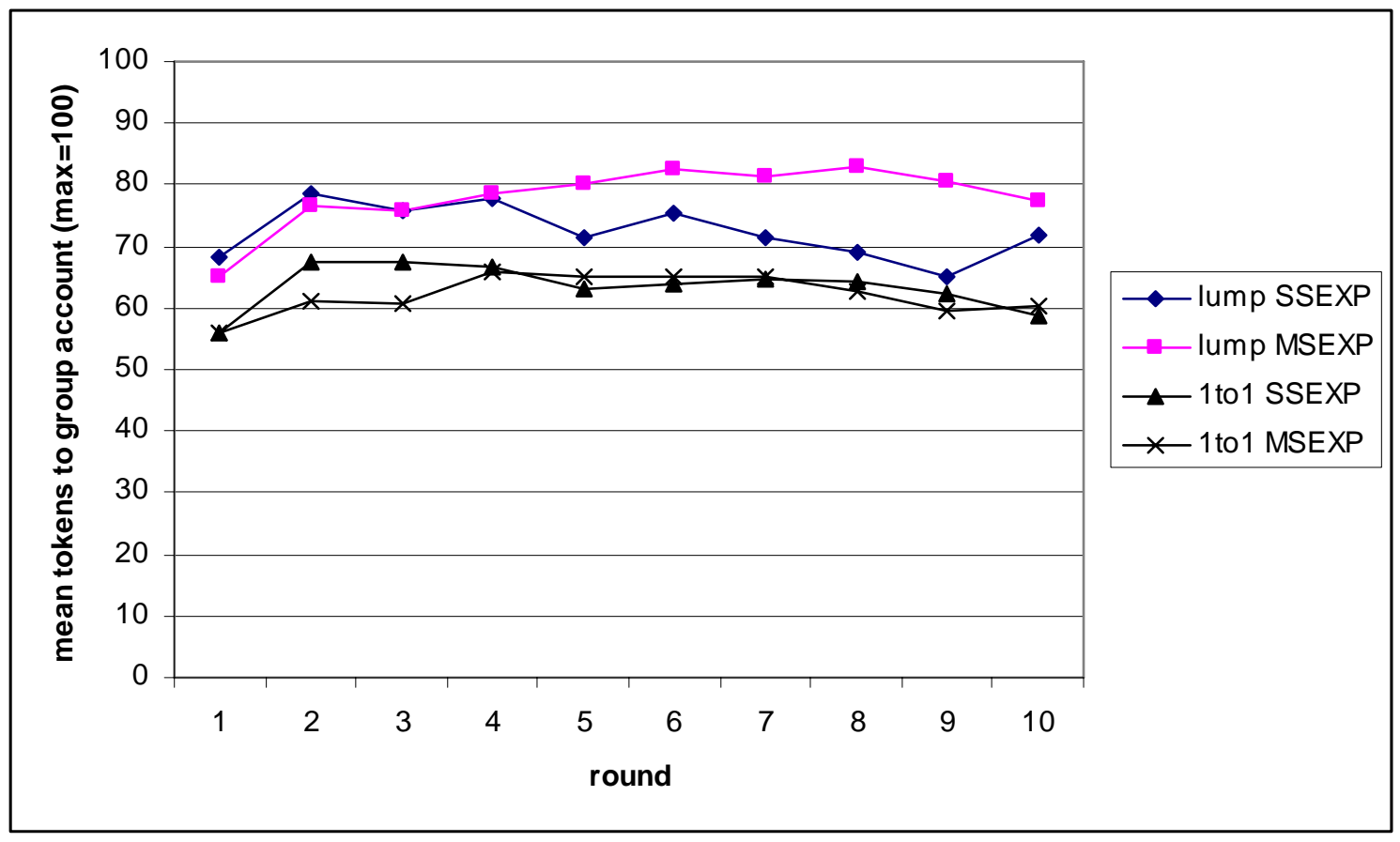


Figure 2. Mean Internal Group-Account Allocations: Group Size 4

Figure 2a. Lump-sum setting

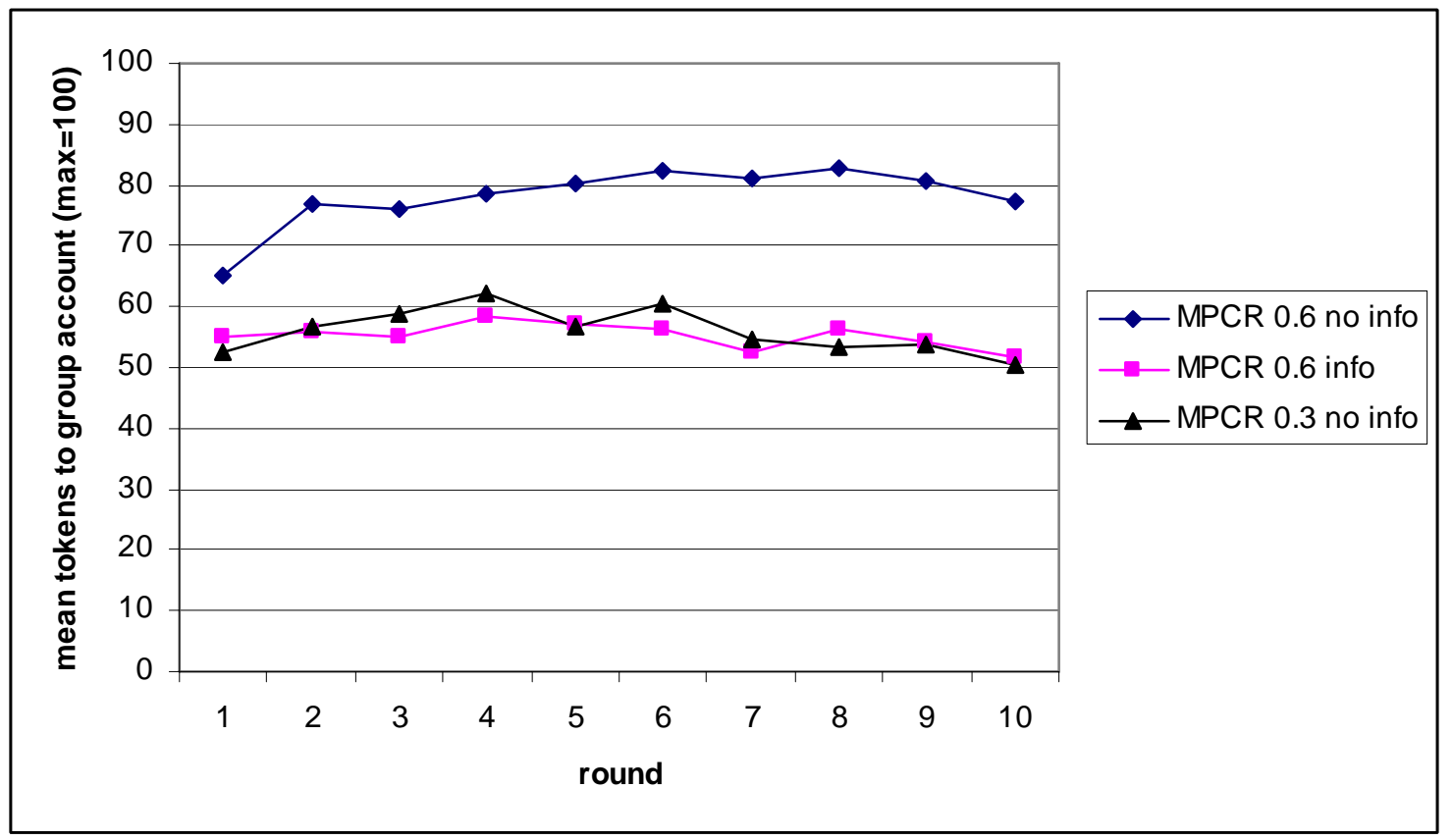

Figure 2b. One-to-one setting

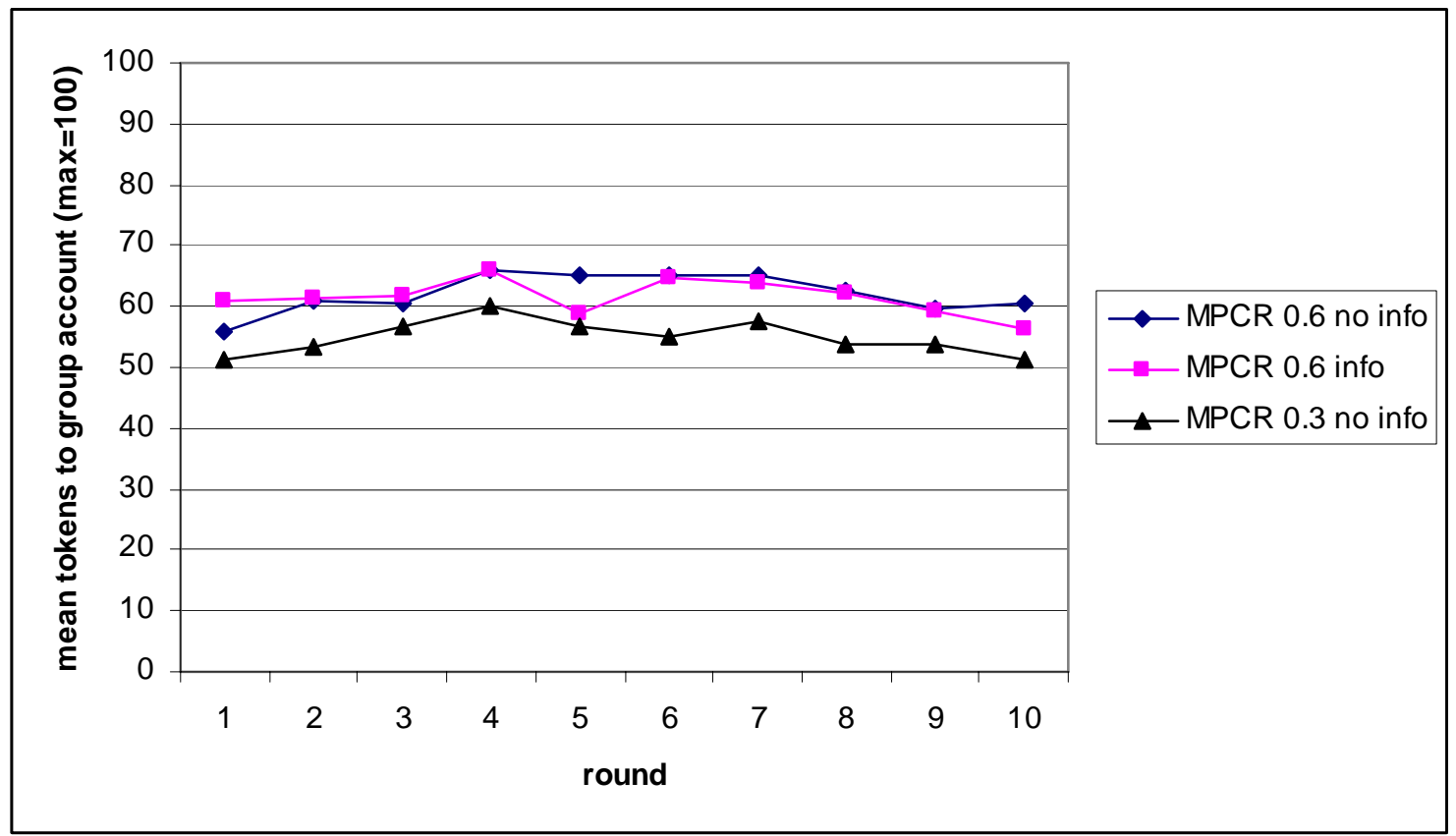


Figure 3. Mean Internal Group-Account Allocations: Group Size 20

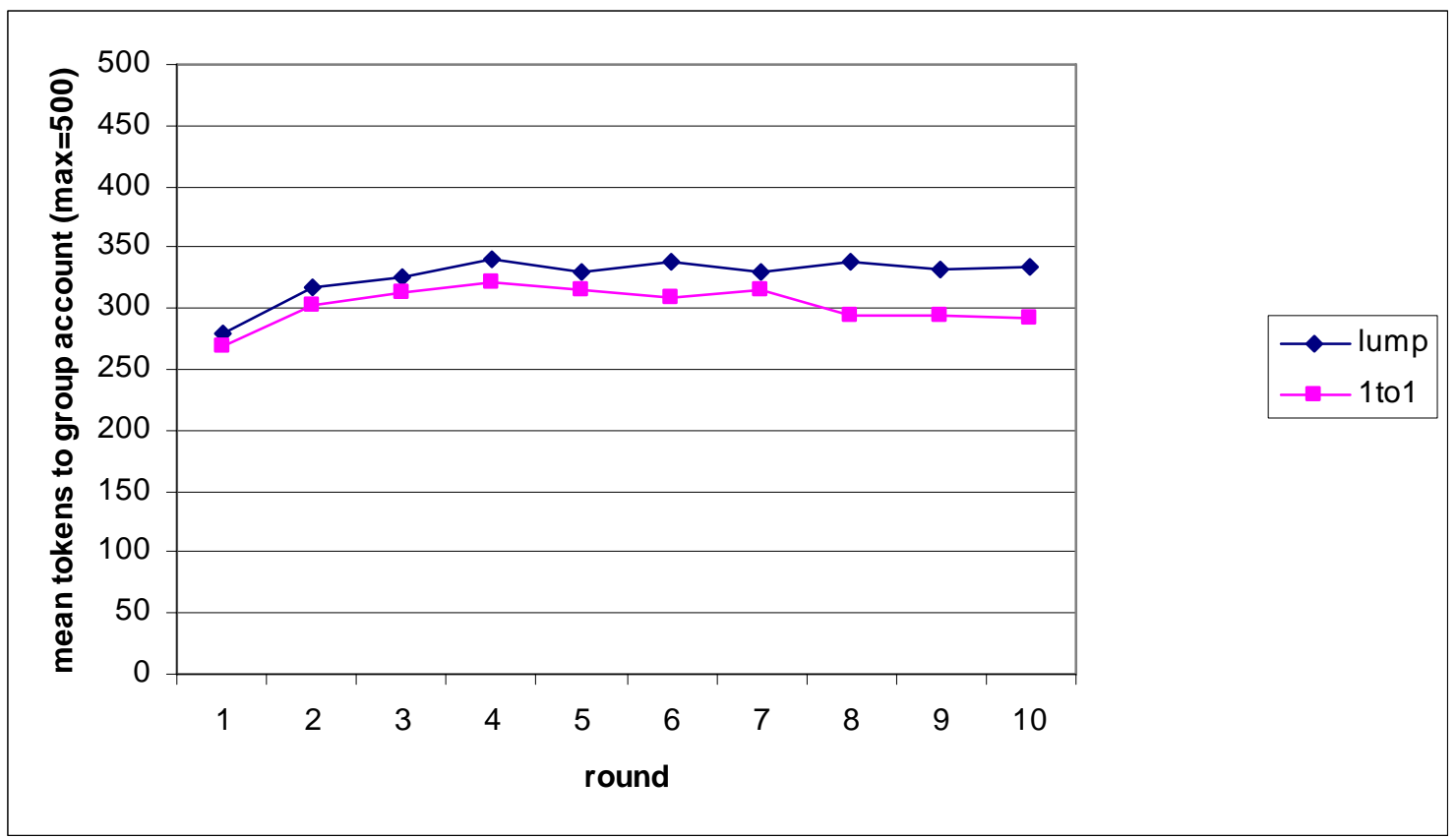


Figure 4. Individual Allocations to the Group Account Across All rounds: Group Size 4

Figure 4a. Lump-sum setting

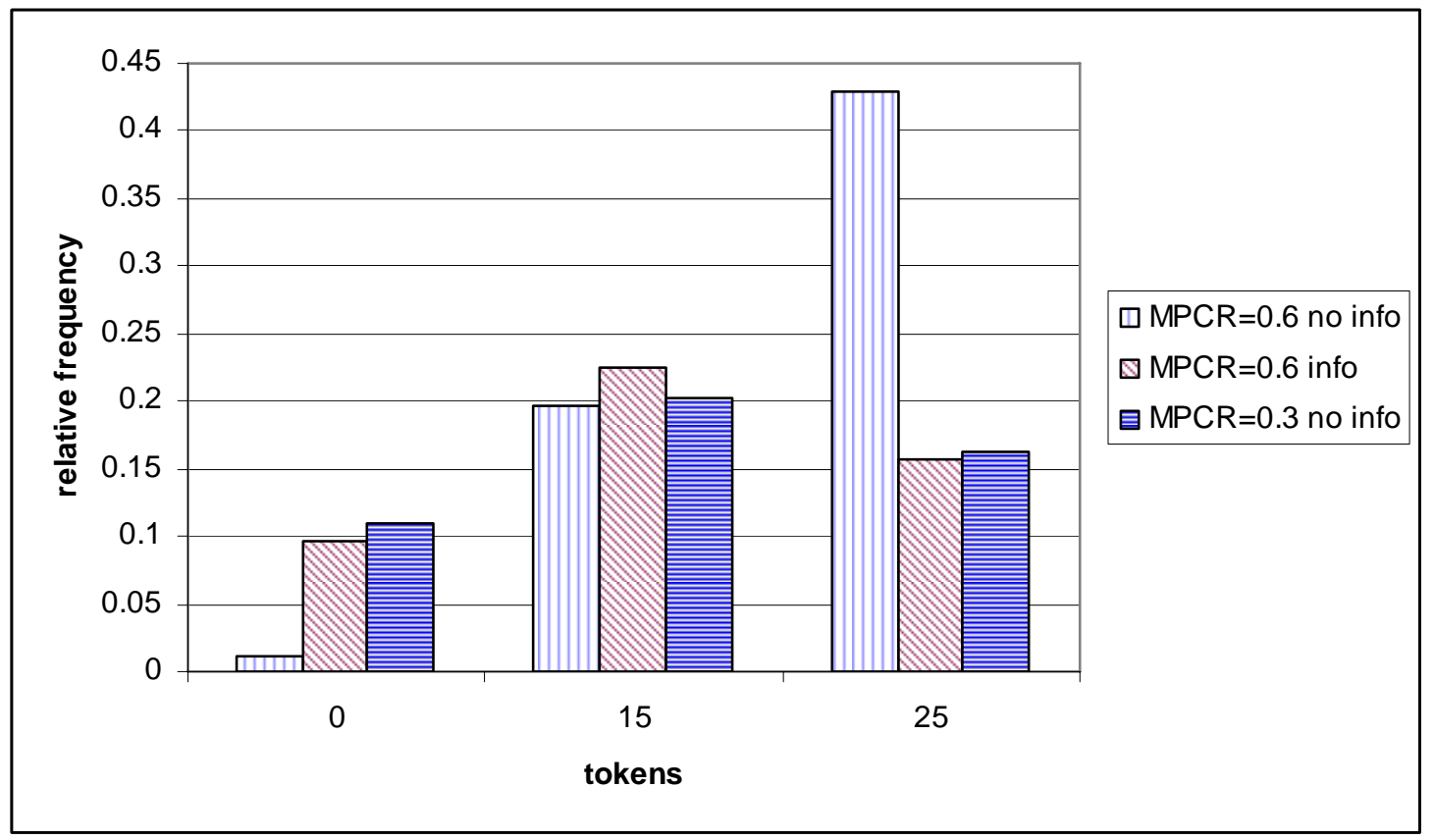

Figure $4 \mathrm{~b}$. One-to-one setting

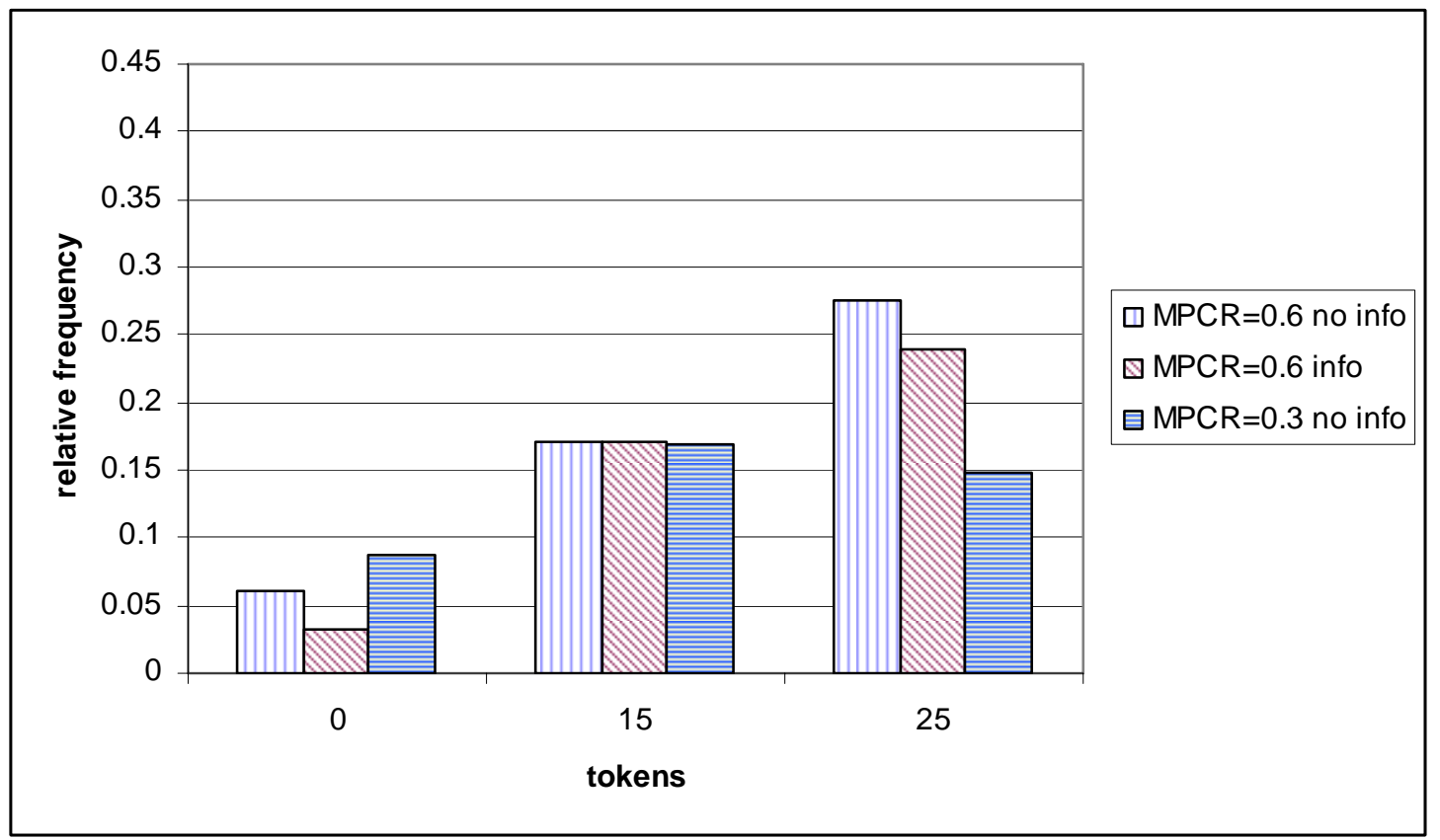


Figure 5: Individual Allocations to the Group Account Across All Rounds: Group Size 20

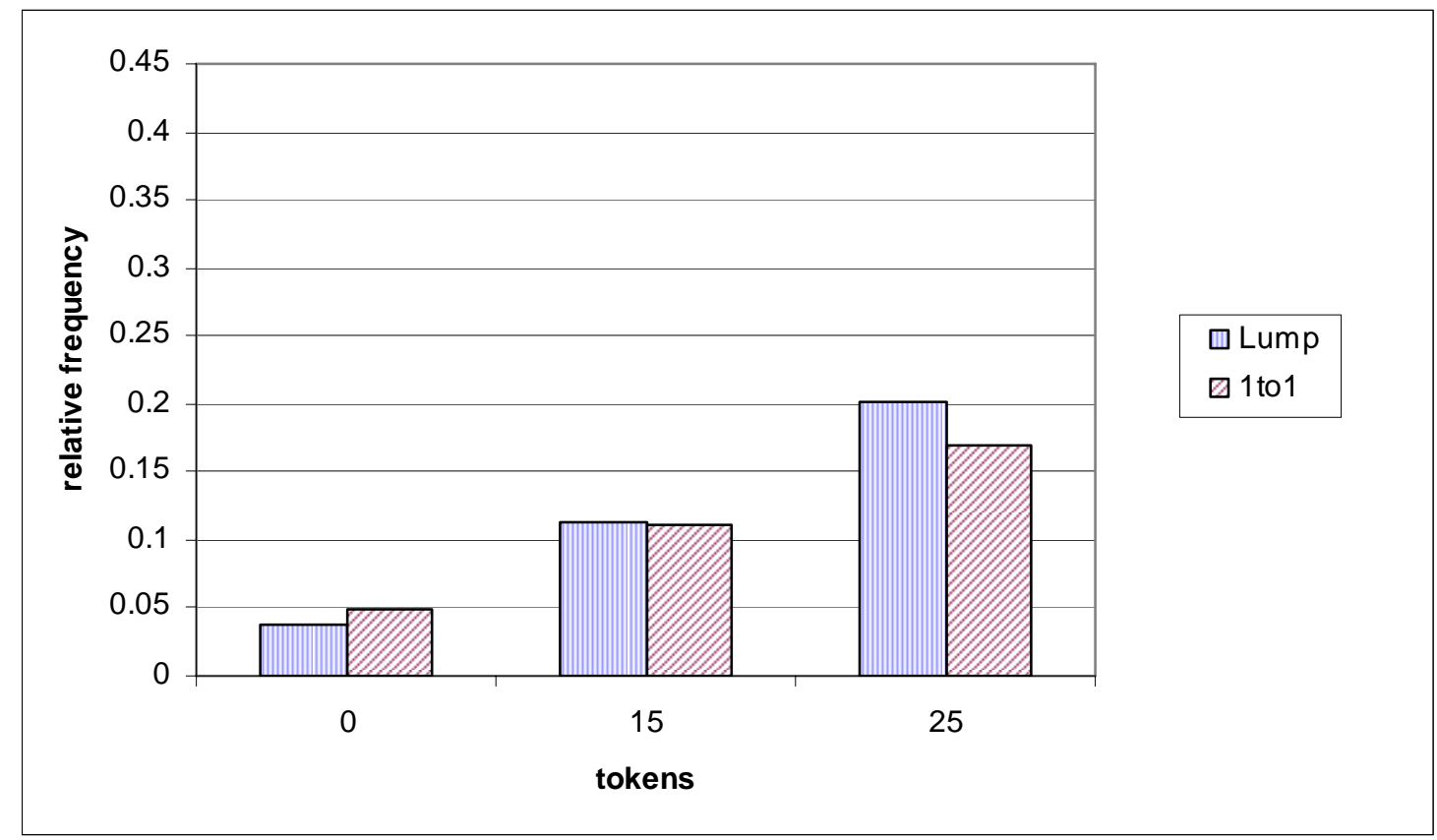




\title{
Appendix. Launch Handout Distributed to Students
}

\author{
Group vs. Private Investment Exercise \\ Second Semester 2007-08
}

You will have the opportunity to earn extra-credit points in a decision-making exercise referred to as the "Group Investment Exercise." Your participation in this exercise is totally voluntary. It is possible to get an A+ in this class based solely on your examination scores. Extra-credit points can only improve upon the course grade you would earn based solely on your exam scores.

The exercise consists of a series of ten decision rounds. In each round you will choose to allocate "tokens" between a "PRIVATE ACCOUNT" and a "GROUP ACCOUNT". When you log into the exercise for the first time (Round 1) the computer will present detailed instructions describing the exercise. After finishing the instructions you will make your allocation decision for Round 1. You will be able to review the instructions during all subsequent rounds if you wish to do so.

\section{Cash Rewards}

The computerized instructions explain that you will earn an amount of money based on the outcomes from all decision rounds. Your actual cash earnings in this exercise will be determined as follows: at the conclusion of the exercise a student will be drawn at random and paid in cash four times their final earnings shown at the end of the exercise. This process of randomly choosing students for cash payments will be repeated until the total of all cash payments is greater than or equal to $\$ 100$, at which time the cash payment process will stop. To be eligible for a cash reward, you must $\log$ on to NovaNET and enter a decision for at least half of the decision rounds in the exercise.

\section{Extra-Credit Rewards}

In addition to the cash rewards discussed above, you will receive extra-credit points based on: 1) your performance as measured by your earnings over all decision rounds, and 2) your participation as measured by the number of rounds in which you log onto NovaNET, view the results from the previous round, and enter a decision.

The score recorded in the NovaNET gradebook summarizing your performance in this extra-credit exercise will be generated using the following "performance index" formula:

100 x [(Actual Earnings - Min. Possible Earnings) / (Max. Possible Earnings - Min. Possible Earnings)].

For each individual, this score can range from 0 (if the individual's actual earnings are equal to the minimum possible earnings) to 100 (if the individual's actual earnings are equal to the maximum possible earnings). This score will be multiplied by a gradebook weight of .015 to determine the number of extra-credit points received. For example, if an individual's performance index score is 80 that person will have $80 \times .015=1.2$ extra-credit points added to their final average for the course. The maximum performance-based extra credit from this exercise is 100 $\mathrm{x} .015=1.5$ points, and the minimum is 0 points. It is important to realize that your performance in this exercise is not based on a rank ordering of student earnings; it is possible for everyone in the class to earn either a small percentage or a large percentage of the maximum number of extra-credit points available in this exercise.

In addition to the extra-credit points based on your final earnings, you will receive .15 of an extra-credit point for each round in which you participate by logging onto NovaNET and entering a decision. After the exercise is finished, the number of rounds in which you participated will be recorded in the gradebook with an associated weight of .15 . Thus, you can receive $10 \times .15=1.5$ additional extra-credit points by simply participating in all ten decision rounds. 


\section{Accessing the Exercise}

You can access the exercise on the NovaNET computer network from any of the Windows-based UITS student technology centers on campus. If you'd like to try installing the NovaNET access software on your home computer, go to Professor Williams' web site: www.indiana.edu/ arlwilli. Click the link in the lower-left frame titled "Download NovaNET Portal" then follow the instructions to download and install the software on your computer. In the STC's, access to NovaNET is available by clicking with the left mouse button on "START" in the lower-left corner of the Windows main display. After opening the START menu, use the mouse to point to "Programs" then "Communications" then click the left mouse button on "NovaNET 3.3". This will launch the NovaNET access software. After a delay of a few seconds you should be presented with the NovaNET login page asking for your NovaNET group and name. To access the extra-credit exercise you must: 1) log into the NovaNET computer network, and 2) log into the NovaNET application program that runs the market.

Feel free to discuss any aspect of this extra-credit exercise with classmates if you care to do so. However, since extra-credit points are awarded for participation in the market, it is an act of academic dishonesty to have someone else enter your decisions for you.

To log on to NovaNET type your "NovaNET group" and "NovaNET name" as follows.

$$
\text { NovaNET group: iuecon NovaNET name: } \underline{\mathbf{v c m}}
$$

After you successfully log on, you will be automatically routed to the "Group Investment Exercise" title page and asked to type your "class file" and your last name. Use the following information.

Class file: $\underline{\text { aw321 }}$

Roster name: first 6 letters of your last name plus the last 4 numbers in your ten-digit IU ID number

After logging in for Round 1, you will be routed to a set of instructions that describe the extra-credit exercise. The first round will probably take less than 15 minutes (feel free to take all the time you find necessary). Entering your decision for subsequent rounds will take less time since you do not have to read the instructions unless you desire to do so. Your allocation decisions are automatically stored by the computer.

\section{Timing of the Decision Rounds}

Round 1 begins after class today.

Round 1 ends and Round 2 begins at noon on Wednesday, 3/19. (The Wednesday after Spring Break.)

Round 2 ends and Round 3 begins at midnight (11:59:59pm) on Saturday, 3/22.

Round 3 ends and Round 4 begins at noon on Wednesday, 3/26.

Round 4 ends and Round 5 begins at midnight on Saturday, 3/29.

Round 5 ends and Round 6 begins at noon on Wednesday, 4/2.

Round 6 ends and Round 7 begins at midnight on Saturday, 4/5.

Round 7 ends and Round 8 begins at noon on Wednesday, $4 / 9$.

Round 8 ends and Round 9 begins at midnight on Saturday, 4/12.

Round 9 ends and Round 10 begins at noon on Wednesday, 4/16.

Round 10 ends at midnight on Saturday, 4/19.

You must work through the instructions and enter a decision for the first round in order to participate in subsequent rounds. Anyone who misses Round 1 is eliminated from further participation and will receive zero extra-credit points. While network or server outages are very rare, it is strongly recommended that you not wait until the last day to log into the first round. It is your responsibility to take into account the fact that any networked computing resource could be unexpectedly unavailable from time to time. 


\section{Notification of Participation in Research Project} IRB Study \#06-11254

The data collected in this class exercise are part of a research project on economic decision making being conducted by Professors James Walker and Arlington Williams of the Department of Economics. When you log into the exercise for the first time, you must choose whether or not your decisions are included as part of this research. The information given below will be available to you online when you are asked to allow or deny research consent. This is part of the standard procedures used by Indiana University for research using human subjects.

\section{INFORMED CONSENT STATEMENT INDIANA UNIVERSITY - BLOOMINGTON}

You will first proceed through a set of instructions on the NovaNet computer system that describe the economic decision making problem. You will then participate in a series of decision making rounds. Your decision in each round will be how to allocate an endowment of tokens between two accounts, a private account and a group account. As explained in the class handout, your decisions, along with the decisions of others in your group, will determine the extra-credit you receive, as well as the cash you might earn through a procedure where participants' names are drawn randomly for cash payments. As noted on the handout, the decision exercise will last six weeks. On average, the instructions require less than 15 minutes, and each of the 10 decision rounds less than 5 minutes. Over the course of three years, this study plans to collect decisions from over 700 individuals in similar decision making settings.

\section{RISKS}

Your full name and ID number will not be recorded in this exercise; however, there may be a minimal risk of loss of confidentiality.

\section{BENEFITS of THIS STUDY}

Your decisions and those of others in this study will be used by the researchers for both education and research purposes. The research will expand our understanding of individual behavior in group decision making settings. Course extra credit and the potential for cash benefits to you are discussed below.

\section{ALTERNATIVES TO TAKING PART IN THE STUDY}

After reading this informed consent statement, you will have the option of choosing whether or not to have your decisions included as part of the research data. You also have the option not to participate in this decision exercise.

\section{CONFIDENTIALITY}

Your individual decisions will remain anonymous to other participants. Your identity will never be revealed in academic papers produced by this research. All decisions are recorded using a personal identifier containing only the first six letters of your last name and the last four numbers of your I.U. identification number. The researchers intend to keep the computerized database containing your personal identifier and decisions confidential, but absolute confidentiality can not be guaranteed. For example, personal information may be disclosed if required by law. The data may also be shared with other researchers, but only in a manner that cannot be linked to a particular individual.

For quality assurance and data analysis, certain individuals and organizations may access the research database that will include your decisions in this exercise. These include the study investigators, their research associates, the I.U.B. Institutional Review Board or its designees, the study sponsor, the Department of Economics, and (as allowed by law) state or federal agencies, specifically the Office for Human Research Protections.

\section{COMPENSATION}

As explained in the class handout, extra credit and the possibility of cash earnings in this exercise do not depend on whether you choose to having your decisions used as part of the research.

\section{COSTS OF PARTICIPATION}

Other than your time, there are no costs to you associated with participation in this exercise.

\section{CONTACT}

If you have questions at any time about the study or the procedures, you may contact the researchers: Professor James Walker, Wylie Hall 240, (812) 855-2760, walkerj@indiana.edu, or Professor Arlington Williams, Wylie Hall 202, (812) 855-4564,williama@indiana.edu.

For questions about your rights as a research participant or to discuss problems, complaints or concerns about a research study, or to obtain information, or offer input, contact the I.U.B. Human Subjects office, 530 E Kirkwood Ave, Carmichael Center, L03, Bloomington IN 47408, 812-855-3067 or by email at iub_hsc@indiana.edu. 